\title{
Impact of Oral Conditions and Subjective Factors on Academic Performance
}

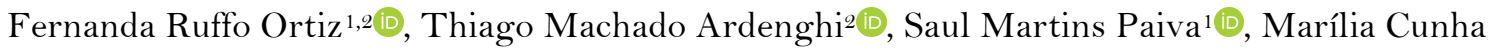 \\ Maroneze $^{2}$ (1), Isabela Almeida Pordeus ${ }^{1}[0$
}

\begin{abstract}
'Department of Pediatric Dentistry, Federal University of Minas Gerais, Belo Horizonte, MG, Brazil
${ }^{2}$ Department of Stomatology, Federal University of Santa Maria, Santa Maria, RS, Brazil.
\end{abstract}

Correspondence: Fernanda Ruffo Ortiz, Av. Roraima, 1000, Prédio 26F, Cidade Universitária, Camobi, Santa Maria, RS, Brazil.97105-900. E-mail: fernandaruffoortiz@gmail.com

Academic Editor: Alessandro Leite Cavalcanti

Received: 04 November 2020 / Review: 28 December 2020 / Accepted: 01 February 2021

How to cite: Ortiz FR, Ardenghi TM, Paiva SM, Maroneze MC, Pordeus IA. Impact of oral conditions and subjective
factors on academic performance. Pesqui Bras Odontopediatria Clín Integr. $2021 ;$
https://doi.org/10.1590/pboci.2021.083

\begin{abstract}
Objective: To evaluate the influence of oral health clinical and non-clinical indicators on adolescents' academic performance. Material and Methods: A longitudinal design was performed with a random sample of 1,134 12-year-old Brazilian adolescents. In 2012, the adolescents were clinically assessed by calibrated dentists and investigated about demographics, socioeconomic factors, dental service use, toothache, and verbal bullying related to oral condition via structured questionnaires. The contextual variable was obtained from the city's official database. After two years, 771 adolescents were reassessed. The outcome adolescent's academic performance (good or poor) was collected through official school's register. Multilevel logistic regression analyses were performed to assess associated factors for adolescents' academic performance. Results: Adolescents with toothache (OR 1.74; CI 95\%: 1.05-2.89), who have been a victim of bullying (OR 2.23; CI 95\%: 1.21-4.09), and were male (OR 1.92; CI 95\%: 1.19-3.09) had a lower academic performance. On the other hand, adolescents whose mothers had higher educational levels (OR 1.79; CI 95\%: 1.08-2.97) and belonged to higher-income households (OR 1.95; CI 95\%: 1.18-3.23) had higher academic performance when compared to their peers. Conclusion: Adverse oral conditions, as well as subjective and socioeconomic factors, impacted on adolescents' academic performance.
\end{abstract}

Keywords: Adolescent; Academic Performance; Bullying; Oral Health. 


\section{Introduction}

Adolescence is one of the most rapid and formative phases of human development that enables physical, cognitive, social, and emotional changes [1]. It is a phase in which individuals spend a considerable number of years receiving education [1]. The educational framework has been described as a critical factor that affects young people's lives [2]. Individuals with lower educational levels tend to have impaired oral care [3], low job income [4], and more risk of developing diseases [2].

Academic performance may refer to different aspects for adolescents, such as improving their education to achieve better financial conditions in the future, wanting to be a mirror for their peers, through positive or negative attitudes and behaviors; and being an example at home, as a good student [5]. In addition, the health conditions of young people can affect the health of future generations through the development of habits, behaviors and socioeconomic contexts [Q].

Individuals with worse socioeconomic backgrounds, including schooling, tend to have worse oral [3] and general health conditions [6], as well as behaviors that compromise health over time that are associated with low educational level [7]. Poor educational outcomes are also associated with poor academic performance and cognitive development [8]. Oral disorders and toothache can affect children and adolescents' learning process, leading to poor academic performance [9] and attendance [10]. Similarly, psychosocial problems with peers and school [8] have been associated with difficulties in adolescents' life. Bullying, which is characterized by harmful behaviors in the form of physical or verbal victimization, is considered a public health problem [11]. Being a victim of bullying increases the risk of health problems, changes in emotional wellbeing, social relationships, and academic activities [12,13].

The literature has been inconclusive regarding the relationship between oral health status and academic performance [10,14], and few studies have evaluated socioeconomic conditions in this relationship [14], and contextual variables. To date, no study has evaluated the influence of verbal bullying related to oral conditions on academic performance. This study aims to assess the association between clinical, subjective, socioeconomic and contextual variables on adolescents' academic performance. We hypothesize that oral conditions will be subtly associated with academic performance, and verbal bullying related to oral conditions and socioeconomic variables will best explain this outcome.

\section{Material and Methods}

This paper was guided by the Strengthening the Reporting of Observational Studies in Epidemiology (STROBE) guidelines.

\section{Ethical Approval}

This study was approved in 2012 by the Human Research Ethics Committee of the University (Protocol Number 0127.0.243.000-11) and in 2014 by the University Committee (Protocol Number 30613714.0.0000.5421). Approval from the Education Secretary was obtained and data were collected after participants signed an informed consent form.

\section{Study Design and Sample}

A longitudinal study was performed with adolescents from Santa Maria, a southern city of Brazil. The study started in 2012 with a representative sample of schoolchildren. A two-stage random conglomerate sampling process was followed. The first stage comprised the randomization of 20 public schools [15] out of 
39 schools equally distributed in the city, considering the school's size (small, medium and large). During this period, the city had 3,817 12-year-old adolescents enrolled in public schools [16]. In the second stage, all the 12-year-old adolescents from these 20 schools were invited to participate in the study. Adolescents who were intellectually and emotionally capable of answering questionnaires were considered eligible. The sample was composed of 1.134 adolescents [17].

The sample size of this study was estimated by the mean academic performance (grades on Brazilian Language test) of 63.4 (SD: 16.4) in adolescents with higher household income and a mean academic performance of 58.0 (SD: 17.7) in adolescents with lower household income [18], 95\% confidence interval, 80\% statistical power, and additional $30 \%$ of losses. A minimum sample size was estimated at 409 adolescents.

\section{Data Collection}

Co-variables at the Baseline

Clinical predictors and individual variables were collected at the baseline. Four calibrated dentists performed the clinical examinations in the schools. The calibration process of oral conditions lasted approximately 36 hours. It involved theoretical classes, discussion of criteria for diagnostics, examination of extracted teeth, and the assessment of 20 adolescents who were not included in the final sample [15]. Kappa values (intra and inter-examiner) ranged from 0.77 to 0.85 for dental caries and malocclusion. Exams were conducted under natural light, using a dental mirror and periodontal probe [15]. Prevalence of untreated dental caries and missing teeth were diagnosed through the "D" and "M" components of the DMF-S index (Decayed, Missing, and Filled surfaces of permanent teeth) using the criteria proposed by the World Health Organization [15]. Malocclusion was assessed according to the Dental Aesthetic Index (DAI) [15]. Adolescents were diagnosed with malocclusion when DAI's final score was higher than 25 points.

Data regarding demographic and socioeconomic variables and dental service use were collected through a structured questionnaire that was answered by parents. Demographic and socioeconomic variables were sex, household income, and mother's educational level. Household income was collected according to the Brazilian minimum wage (BMW), which was USD 500 in 2012 and household income analyses were obtained from the median (USD 500 equivalent to 1,000 Reals). Mothers' educational level was collected based on the formal years of study, and dichotomized in those who had completed eight years of formal education (corresponding to primary education in Brazil) and those who did not. Variables related to adolescents' dental service use were the following: visit to the dentist in the past six months ("Yes" or "No"), and reasons for the visit. Then, this last variable was categorized as "routine/checkup" or "toothache".

Verbal bullying related to oral conditions was measured according to adolescents' self-report [19]. In this regard, adolescents answered the following question, "In the last three months, how many times did other children make fun of you or call you nicknames because of your teeth, lips or your mouth?" Answers were ranked from 0 to 4 points $(0=$ never, $1=$ once or twice, $2=$ sometimes, $3=$ often, and $4=$ every day $/$ almost every day). Later, this variable was dichotomized in the absence of bullying (answer 0 ) and presence of bullying (answers 1, 2, 3, and 4).

The Basic Education Development Index (IDEB), which represented the contextual education variable of this study, was obtained through the Brazilian government's data [16,20]. IDEB measures the quality of learning in public schools evaluated by students' promotion, performance means in national exams, and students' flow, represented by the progress of the educational system in Brazil (ranging from 0 to 10). In the analysis, the variable was categorized by medians (5.1) and higher scores indicated a greater quality of education at school. 


\section{Outcome at the Follow-up}

The outcome variable of this study was academic performance. Student data were obtained from school registers at follow-up (year 2014). In Santa Maria city, students are evaluated by the same criteria of subjects (i.e., Portuguese, Mathematics, Science, History and Geography) that range from o to 10, when the approval has been $\geq 5$.0. This form of evaluation is standardized in all schools by education secretary. In Brazil, results of language skills' evaluations are used as a proxy to evaluate academic performance [20] and schools indicate whether a student is approved or reproved at the end of the school year. Therefore, in the statistical analysis, adolescents that were reproved $(<5.0)$ in any grade (according to the adolescent's school) were considered having poor academic performance.

\section{Statistical Analysis}

Data analysis was performed using STATA statistical software, version 14.0 (STATA Corporation, College Station, TX, USA). The sample's characteristics were analyzed using descriptive statistics such as frequency, mean, and standard deviation (SD) regarding data obtained at the baseline (2012) and outcomes from follow-up (2014). Chi-square test was performed to assess the socioeconomic and clinical characteristics of the reassessed and non-reassessed adolescents. The analyses considered the sampling weight using the prefix command ("svy") for complex data samples.

Unadjusted and adjusted analyses were fitted by a multilevel logistic regression model to assess the association between predictor variables and outcome (academic performance). The theoretical model was based in a previous study [14] (Figure 1), including oral health, socioeconomic, subjective variables and additional contextual variable, with possible confounders. Multilevel models were used to account for the two-level structure of the data: individuals (first level) nested within schools (second level). Models considered the random intercept with fixed effect. First, a null model was fitted to assess the percentage of variance of each level. Model 1 was composed of contextual, demographic, and socioeconomic variables. Model 2 comprised clinical variables and verbal bullying adjusted by Model 1 . All covariates with a p-value $\leq 0.20$ in the crude analysis were considered for the adjusted models. The final model comprised the adjusted final analyses of variables with a p-value $<0.05$. Results are shown as odds ratio (OR) and 95\% confidence interval (CI). Finally, the quality of fit of the models was assessed using the deviance (-2* log likelihood) and Median Odds Ratio (MOR).

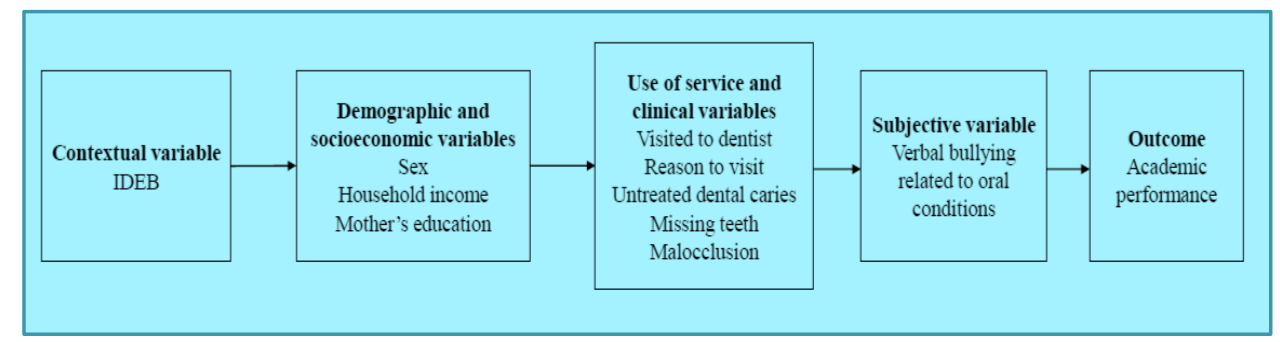

Figure 1. Theorical model for statistical analysis.

\section{Results}

In the evaluation of the characteristics of 1,134 12-year-old participants in 2012, there were more females $(53.8 \%)$, higher household income $(53.7 \%)$, and the majority of mothers had more than eight years of 
education (64.8\%). About $47.3 \%$ of adolescents had visited the dentist because of toothache (26.2\%). A total of 42.1\% had untreated dental caries, and $1.3 \%$ had lost at least one tooth. Adolescents who had suffered verbal bullying related to oral conditions were 15.5\%. After two years, 771 adolescents were reassessed, and 644 adolescents were assessed regarding academic performance outcomes. In this regard, 18.2\% had poor academic performance in 2014 (Table 1). There were no statistical differences for all variables when comparing the reassessed and non-reassessed participants, as seen in the results of the Chi-square test ( $p>0.05$ for all variables).

Table 1. Table 1. Descriptive analysis of sample at baseline (2012) and follow-up (2014).

\begin{tabular}{|c|c|c|c|c|}
\hline Variables & $\begin{array}{c}\text { Baseline } \\
\mathrm{N}(\%)\end{array}$ & $\begin{array}{c}\text { Follow-up } \\
\mathrm{N}(\%)\end{array}$ & $\begin{array}{c}\text { No Follow-up } \\
\text { N (\%) }\end{array}$ & p-value \\
\hline Sex & & & & 0.51 \\
\hline Female & $610(53.8)$ & $410(53.2)$ & $163(44.8)$ & \\
\hline Male & $524(46.2)$ & $361(46.8)$ & $202(55.2)$ & \\
\hline Household Income§ & & & & 0.31 \\
\hline$\geq$ USD 500 & $556(53.7)$ & $384(68.8)$ & $182(56.0)$ & \\
\hline$<$ USD 500 & $480(46.3)$ & $174(31.2)$ & $143(44.0)$ & \\
\hline Mother’s Education§ & & & & 0.16 \\
\hline$\geq 8$ years & $702(64.8)$ & $423(68.3)$ & $233(67.7)$ & \\
\hline$<8$ years & $382(35.2)$ & $197(31.7)$ & $111(32.3)$ & \\
\hline Visited to the Dentist at 6 Months & & & & 0.10 \\
\hline No & $572(52.7)$ & $310(48.9)$ & $169(49.0)$ & \\
\hline Yes & $514(47.3)$ & $324(51.1)$ & $176(51.0)$ & \\
\hline Reason to Visit the Dentist & & & & 0.29 \\
\hline Routine & $778(73.8)$ & $440(75.9)$ & $258(75.9)$ & \\
\hline Toothache & $276(26.2)$ & $140(24.1)$ & $82(24.1)$ & \\
\hline Untreated Dental Caries§ & & & & 0.06 \\
\hline Without & $657(57.9)$ & $432(59.8)$ & $243(66.8)$ & \\
\hline With & $477(42.1)$ & $311(40.2)$ & $121(33.2)$ & \\
\hline Missing Teeth§ & & & & 0.41 \\
\hline No & $1119(98.7)$ & $709(95.5)$ & $362(99.4)$ & \\
\hline At Least 1 Tooth & $15(1.3)$ & $34(4.5)$ & $2(0.6)$ & \\
\hline Malocclusion & & & & 0.68 \\
\hline No & $651(57.5)$ & $375(50.5)$ & $206(56.6)$ & \\
\hline Yes & $482(42.5)$ & $368(49.5)$ & $158(43.4)$ & \\
\hline Verbal Bullying & & & & 0.53 \\
\hline Absent & $958(84.5)$ & $690(92.6)$ & $311(85.4)$ & \\
\hline Present & $176(15.5)$ & $55(7.4)$ & $53(14.6)$ & \\
\hline IDEB & & & & 0.58 \\
\hline$\leq 5.1$ & $627(55.3)$ & $430(55.7)$ & $197(54.1)$ & \\
\hline$>5.1$ & $507(44.7)$ & $341(44.3)$ & $167(45.9)$ & \\
\hline \multicolumn{5}{|l|}{ Outcome } \\
\hline \multicolumn{5}{|l|}{ Academic Performance§ } \\
\hline Good & - & $527(81.8)$ & & \\
\hline Poor & - & $117(18.2)$ & & \\
\hline
\end{tabular}

\$Missing data; *Chi-square test; IDEB: Basic school's Development Index (median 5.1); USD 500 it was equivalent to $\mathrm{R} \$ 1,000$ approximately during the baseline data gathering.

Table 2 shows the unadjusted multilevel regression analysis. The contextual, demographic, socioeconomic, clinical, and subjective variables were associated with poor academic performance. On the other hand, visiting the dentist, untreated dental caries, and malocclusion were not associated with academic performance $(\mathrm{p}>0.05)$. 
Table 2. Unadjusted multilevel logistic regression for academic performance according to contextual, clinical, and non-clinical variables.

\begin{tabular}{|c|c|c|}
\hline \multirow[t]{2}{*}{ Variables } & \multicolumn{2}{|c|}{ Poor Academic Performance } \\
\hline & OR (95\%CI) Crude & p-value \\
\hline \multicolumn{3}{|l|}{ Contextual } \\
\hline \multicolumn{3}{|l|}{ IDEB } \\
\hline$\leq 5.1$ & 1 & \\
\hline$>5.1$ & $0.60(0.36-1.01)$ & 0.05 \\
\hline \multicolumn{3}{|c|}{ Demographic and Socioeconomic } \\
\hline \multicolumn{3}{|c|}{ Sex } \\
\hline Female & 1 & \\
\hline Male & $1.60(1.06-2.43)$ & 0.02 \\
\hline \multicolumn{3}{|l|}{ Household Income } \\
\hline$\geq$ USD 500 & 1 & \\
\hline$<$ USD 500 & $2.60(1.67-4.05)$ & $<0.01$ \\
\hline \multicolumn{3}{|l|}{ Mother's Education } \\
\hline$\geq 8$ years & 1 & \\
\hline$<8$ years & $2.40(1.57-3.67)$ & $<0.01$ \\
\hline \multicolumn{3}{|l|}{ Clinical and Subjective } \\
\hline \multicolumn{3}{|l|}{ Visited to the Dentist } \\
\hline No & 1 & \\
\hline Yes & $0.67(0.43-1.03)$ & 0.07 \\
\hline \multicolumn{3}{|l|}{ Reason to Visit to the Dentist } \\
\hline Routine & 1 & \\
\hline Toothache & $2.23(1.42-3.50)$ & $<0.01$ \\
\hline \multicolumn{3}{|l|}{ Untreated Dental Caries } \\
\hline Without & 1 & \\
\hline With & $1.12(0.74-1.69)$ & 0.60 \\
\hline \multicolumn{3}{|l|}{ Missing Teeth } \\
\hline No & 1 & \\
\hline At Least 1 Tooth & $2.23(1.02-4.89)$ & 0.04 \\
\hline \multicolumn{3}{|l|}{ Malocclusion } \\
\hline No & 1 & \\
\hline Yes & $0.96(0.63-1.45)$ & 0.84 \\
\hline \multicolumn{3}{|l|}{ Verbal Bullying } \\
\hline Absent & 1 & \\
\hline Present & $2.19(1.32-3.64)$ & $<0.01$ \\
\hline
\end{tabular}

The adjusted multilevel analysis is presented in Table 3. In the final model, individuals with toothache had poor academic performance (OR 1.74; CI95\%: 1.05-2.89) than those who visited the dentist for routine reasons. Adolescents who have been bullied at the baseline also had poor academic performance (OR 2.23; CI95\%: 1.21-4.09). In addition, males had poorer performance at school (OR 1.92; CI95\%: 1.19-3.09) than females. Adolescents who belonged to households with lower income (OR 1.95; CI95\%: 1.18-3.23) and had mothers with lower educational level (OR 1.79; CI95\%: 1.08-2.97) presented poorer academic performance compared to their peers.

Table 3. Adjusted multilevel logistic regression for academic performance according to contextual, clinical, and non-clinical variables.

\begin{tabular}{lcccc}
\multicolumn{1}{c}{ Variables } & $\begin{array}{c}\text { Null Model } \\
\text { OR }(95 \% \mathrm{CI})\end{array}$ & $\begin{array}{c}\text { Poor Academic Performance } \\
\text { OR }(95 \% \mathrm{CI})\end{array}$ & $\begin{array}{c}\text { Model } 2 \\
\text { OR }(95 \% \mathrm{CI})\end{array}$ & $\begin{array}{c}\text { Final Model } \\
\text { OR }(95 \% \mathrm{CI})\end{array}$ \\
\hline $\begin{array}{l}\text { Fixed Effects } \\
\text { Intercept } \\
\text { Baseline Variables } \\
\text { IDEB }\end{array}$ & $0.21(0.16-0.28)^{* * * *}$ & $0.08(0.05-0.14)^{* * * *}$ & $0.07(0.03-0.14)^{* * * *}$ & $0.05(0.03-0.10)^{* * *}$ \\
& & & &
\end{tabular}




\begin{tabular}{|c|c|c|c|c|}
\hline$\leq 5.1$ & & 1 & 1 & - \\
\hline$>5.1$ & & $1.09(0.68-1.74)$ & $1.07(0.56-2.04)$ & - \\
\hline \multicolumn{5}{|l|}{ Sex } \\
\hline Female & & 1 & 1 & 1 \\
\hline Male & & $1.68(1.08-2.61)^{*}$ & $1.84(1.13-2.98)^{* * *}$ & $1.92(1.19-3.09)^{* *}$ \\
\hline \multicolumn{5}{|l|}{ Household Income } \\
\hline$\geq$ USD 500 & & 1 & 1 & 1 \\
\hline$<$ USD 500 & & $2.14(1.33-3.43)^{* *}$ & $1.78(1.06-2.99)^{*}$ & $1.95(1.18-3.23) * *$ \\
\hline \multicolumn{5}{|l|}{ Mother's Education } \\
\hline$\geq 8$ years & & 1 & 1 & 1 \\
\hline$<8$ years & & $1.93(1.21-3.07)^{* *}$ & $1.71(1.02-2.87)^{*}$ & $1.79(1.08-2.98)^{*}$ \\
\hline \multicolumn{5}{|l|}{ Visited to the Dentist } \\
\hline Yes & & & 1 & - \\
\hline No & & & $0.76(0.46-1.24)$ & - \\
\hline \multicolumn{5}{|l|}{ Reason to Visit to the Dentist } \\
\hline Routine & & & 1 & 1 \\
\hline Toothache & & & $1.72(1.02-2.89)^{*}$ & $1.74(1.05-2.89)^{*}$ \\
\hline \multicolumn{5}{|l|}{ Missing Teeth } \\
\hline No & & & 1 & - \\
\hline At least 1 tooth & & & $1.25(0.46-1.24)$ & - \\
\hline \multicolumn{5}{|l|}{ Verbal Bullying } \\
\hline Absent & & & 1 & 1 \\
\hline Present & & & $2.18(1.17-4.06)^{* *}$ & $2.23(1.21-4.09)^{* * *}$ \\
\hline Deviance $=(-2$ loglikelihood $)$ & 606.95 & 511.43 & 457.44 & 457.44 \\
\hline MOR & 1.44 & 1.07 & 1.48 & 1.48 \\
\hline
\end{tabular}

*p<0.05; ** $\leq 0.01 ;{ }^{*} * * \mathrm{p}=0.000 ;$ Null Model: empty model, represents unconditional model; Model 1: contextual, demographic and socioeconomic variables; Model 2: model 1 plus clinical and subjective variables; Final Model: fully model, adjusted variables; OR: Odds Ratio; CI: Confidence Interval; MOR: Median Odds Ratio; IDEB: Basic School's Development Index (median 5.1); USD500 it was equivalent to $\mathrm{R} \$ 1000$ approximately during the baseline data gathering.

\section{Discussion}

This longitudinal design demonstrated that adverse oral conditions and socioeconomic factors were associated with poor academic performance. To our knowledge, this is the first study to evaluate the impact of clinical factors and verbal bullying related to oral conditions on the academic performance of adolescents.

The association between oral conditions and educational outcomes has been demonstrated previously $[9,10]$. Although dental caries and malocclusion were not associated with the outcome in our analysis, its physical and emotional consequences, such as toothache and verbal bullying, were associated. It is important to point out that sometimes dental caries and malocclusion may not be perceived or considered as a problem by the adolescent, at a first moment. However, when adolescents experience pain or are bullying victims due to oral conditions, this situation changes, that is, they begin to perceive as a problem and suffer for it. So, toothache and verbal bullying affect adolescents' routine generating psychosocial impacts at this stage [12,21].

Toothache was associated to adolescents' academic performance, showing that oral conditions indeed affect school activities. This condition may cause an impact on social behavior, sleepless nights [21], school absences, and reduced attention leading to poor academic performance due to pain [22]. It can be assumed that poor oral health impairs school activities through physical discomfort and social exclusion [23]. A recent study showed that adolescents with oral problems reported functional limitations such as difficulties in sleeping, talking, enjoying food, and sadness because of the absence of good oral health. They also expressed concerns about the opinion of other people regarding their oral health status when performing daily school activities such as tasks, attending school, and interacting with other people [24]. During adolescence, individuals search for social approval and inclusion in groups, besides repeating behaviors similar to their 
peers, are important aspects in the life of an adolescent [1]. All these behavioral factors can cascade over a student affecting oral conditions and academic performance.

In this study, adolescents who reported being bullied about their oral condition were more likely to show worse academic performance. Bullying refers to an imbalance of power through repeated negative actions between the victim and the bully. Individuals who have been bullied during childhood and adolescence have higher rates of anxiety, panic disorder and depression in adulthood [12]. Victims tend to develop an antisocial personality [12], with poor affective and social relationships, as well as few friends. When adolescents are bullied, their functioning in social and school settings may be impaired because of peer relationships or behavior problems [25]. Therefore, peer rejection has been associated with negative emotional reactions, interfering with coping behaviors. On the other hand, greater social competence attenuates the magnitude of negative emotional responses caused by peer rejection [26]. Besides psychological and health consequences, bullying has been found to be mediated by psychosocial problems or directly related to academic performance [27]. Victims of bullying have high levels of rejection, low levels of popularity, and exclusion from subgroups, which may result in less interest in school [13].

Regarding sex, males presented poorer academic performance than females [18,28]. One possible explanation is that the boys appear to be more engaged in risk factors and harmful behaviors [29]. On the other hand, girls were more engaged in healthy behaviors and looking for healthier ways of being, not only regarding health but also in other aspects of life [29].

Our findings indicate that academic performance has a relationship with socioeconomic background. Mothers with higher educational level and higher household incomes were associated with better academic performance of adolescents. These results are supported by other studies [18,28]. Education and income are considered socioeconomic variables [30]. In addition, the environment in which the individual lives and social relationships influence the behaviors and attitudes of children [31]. Still, families with better socioeconomic conditions tend to have more information and use the dental service in a preventive way. The effect of socioeconomic background might persist throughout life [3] and this may be associated with different health and educational outcomes.

The findings of this study can also be showed to general health. Academic performance is affected by health and socioeconomic position [5]. Parents' educational and socioeconomic level provided the greatest influence in children's lives, indicating that home environment a determining factor. When the support of family is not favorable (i.e., parents with low education or who do not stimulate the education of their children), it seems to reflect on school behavior [5] and children's health [11]. Thus, parents' engagement and the importance given to school are positive factors regarding the learning of young children and adolescents.

This study presents strengths and limitations. One of its strongest aspects is that the research design is longitudinal, with a two-year follow-up. The outcome was collected only in 2014 to try to verify the temporal relationship between the associations. Conversely, our analyses are cross-sectional. Academic performance was collected in just one moment and the possibility of reversing the causality bias cannot be disregarded. Moreover, academic performance was provided by school registers; therefore, some data might be missing, although the sample calculation was attained. Through the data provided, only approved and reproved categorization was possible. Regarding the possible changes inherent to the follow-up time, the sensitivity analysis did not show differences between missing data and participants, including socioeconomic and clinical variables. This study included only public schools, which is another limitation. However, public schools accounted for $85 \%$ of the students of the city. As an advantage, the present study used different factors (i.e., 
demographic, socioeconomic, clinical, subjective, and contextual) to evaluate the relationship with educational outcomes. In this regard, multilevel analyses were performed to verify the variance of each level. Although we have included school contextual variables, we have failed in gathering information on school's variables, such as the number of teachers and infrastructure, as well as variables that impair sleep which may also affect adolescents' academic performance. In addition, verbal bullying related to oral conditions was assessed by only one question and other factors related to bullying were not included. However, previous studies have also utilized this methodology [19]. Despite these limitations, we believe that the temporal relationship of the impact of oral conditions on academic performance over time has been confirmed. Moreover, the findings are important for future publications, which can explore in more detail these relations.

Global programs believe that educational factors are important in influencing behavior, health, and wellbeing of adolescents. Moreover, education is a major determinant of adolescent and subsequent adult health [1]. This research paper provided clarification and support regarding the association between oral health and education, which is becoming important in the implementation of strategies aimed at improving the educational level of the population. Intersectoral actions among health and education professionals are necessary to prevent dental injuries and promote adolescents' self-esteem, as well as preventive dental visits, strategies to prevent bullying, and family encouragement regarding education, especially in groups with socioeconomic disadvantages.

\section{Conclusion}

Adverse oral conditions, as well as subjective and socioeconomic factors, were associated with adolescents' academic performance.

\section{Authors' Contributions}

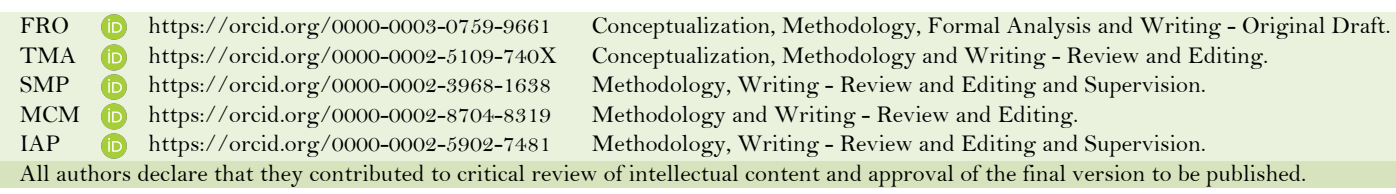

\section{Financial Support}

This study was financed in part by the Coordenação de Aperfeiçoamento de Pessoal de Nível Superior - Brasil (CAPES). We thank by supported the study the institutions: Conselho Nacional de Desenvolvimento Científico e Tecnológico - CNPq (Grants 477118/2013-5 and 308141/2012-1) and the Fundação de Amparo à Pesquisa do Rio Grande do Sul - FAPERGS (Grant 2381-2551/14-0).

\section{Conflict of Interest}

The authors declare no conflicts of interest.

\section{Data Availability}

The data used to support the findings of this study can be made available upon request to the corresponding author.

\section{Acknowledgments}

We grateful all adolescents; their families and schools by participation.

\section{References}

[1] World Health Organization. Global Accelerated Action for the Health of Adolescents (AA-HA!): Guidance to Support Country Implementation. Geneva: World Health Organization; 2017. 
[2] Blum RW, Nelson-Mmari K. The health of young people in a global context. J Adolesc Health 2004; 35(5):402-18. https://doi.org/10.1016/j.jadohealth.2003.10.007

[3] Thomson WM, Poulton R, Milne BJ, Caspi A, Broughton JR, Ayers KMS. Socioeconomic inequalities in oral health in childhood and adulthood in a birth cohort. Community Dent Oral Epidemiol 2004; 32(5):345-53. https://doi.org/10.1111/j.1600-0528.2004.00173.x

[4] Haas SA. Health selection and the process of social stratification: the effect of childhood health on socioeconomic attainment. J Health Soc Behav 2006; 47(4):339-54. https://doi.org/10.1177/002214650604700403

[5] Ruijsbroek A, Wijga AH, Gehring U, Kerkhof M, Droomers M. School performance: a matter of health or socioeconomic background? Findings from the PIAMA birth cohort study. PloS ONE 2015; 10(8):e0134780. https://doi.org/10.1371/journal.pone.0134780

[6] Frenz P, Kaufman JS, Nazzal C, Cavada G, Cerecera F, Silva N. Mediation of the effect of childhood socioeconomic position by educational attainment on adult chronic disease in Chile. Int J Public Health 2017; 62(9):1007-17. https://doi.org/10.1007/s00038-017-0996-z

[7] Koivusilta L, Arja R, Andres V. Health behaviours and health in adolescence as predictors of educational level in adulthood: a follow-up study from Finland. Soc Sci Med 2003; 57(4):577-93. https://doi.org/10.1016/s0277-9536(02)00405-7

[8] Haas SA, Fosse NE. Health and the educational attainment of adolescents: Evidence from the NLSY97. J Health Soc Behavior 2008; 49(2):178-92. https://doi.org/10.1177/0022 14650804900205

[9] Guarnizo-Herreño CC, Lyu W, Wehby GL. Children's oral health and academic performance: evidence of a persisting relationship over the last decade in the United States. J Pediatric 2019; 209:183-9. https://doi.org/10.1016/j.jpeds.2019.01.045

[10] Ribeiro APAD, Almeida RF, Mendonça JGA, Leal SC. Oral health and its effect on the academic performance of children and adolescents. Pediatr Dent 2018; 40(1):12-7.

[11] United Nations International Children's Emergency Fund. Hidden in Plain Sight: A Statistical Analysis of Violence Against Children. New York: UNICEF, 2014.

[12] Copeland WE, Wolke D, Angold A, Costello EJ. Adult psychiatric outcomes of bullying and being bullied by peers in childhood and adolescence. JAMA Psychiatry 2013; 70(4):419-26. https://doi.org/10.1001/jamapsychiatry.2013.504

[13] Hanish LD, Guerra NG. A longitudinal analysis of patterns of adjustment following peer victimization. Dev Psychopathol 2002; 14(1):69-89. https://doi.org/10.1017/s0954579402001049

[14] Rebelo MAB, Rebelo Vieira JM, Pereira JV, Quadros LN, Vettore MV. Does oral health influence school performance and school attendance? A systematic review and meta-analysis. Int J Paediatr Dent 2019; 29(2):138-48. https://doi.org/10.1111/ipd.12441

[15] World Health Organization. Oral Health Surveys: Basic Methods. $4^{\text {th }}$ ed. Geneva: World Health Organization; 1997.

[16] Instituto Brasileiro de geografia e Estatística. Censo Demográfico, 2010. Available from: https://censo2010.ibge.gov.br. [Accessed on July 15, 2020]. [In Portuguese].

[17] Tomazoni F, Vettore MV, Zanatta FB, Tuchtenhagen S, Moreira CHC, Ardenghi TM. The associations of socioeconomic status and social capital with gingival bleeding among schoolchildren. J Public Health Dent 2017; 77(1):21-9. https://doi.org/10.1111/jphd.12166

[18] Piovesan C, Antunes JLF, Mendes FM, Guedes RS, Ardenghi TM. Influence of children's oral health-related quality of life on school performance and school absenteeism. J Public Health Dent 2012; 72(2):156-63. https://doi.org/10.1111/j.1752-7325.2011.00301.x

[19] Barasuol JC, Soares JP, Castro RG, Giacomin A, Gonçalves BM, Klein D, et al. Untreated dental caries is associated with reports of verbal bullying in children 8-10 years old. Caries Res 2017; 51(5):482-8. https://doi.org/10.1159/000479043

[20] Instituto Nacional de Estudos e Pesquisas Educacionais Anísio Teixeira. Portal Ideb. 2013. Available from: http://portal.inep.gov.br/web/portal-ideb/portal-ideb. [Accessed on August 23, 2020]. [In Portuguese].

[21] Perazzo MF, Gomes MC, Neves ÉTB, Firmino RT, Barros AA, Silva LC, et al. Self-perceptions of the impact of oral problems on the social behavior of preschoolers. JDR Clin Trans Res 2019; 17:2380084419894576. https://doi.org/10.1177/2380084419894576

[22] Jackson SL, Vann JrWF, Kotch JB, Pahel BT, Lee JY. Impact of poor oral health on children's school attendance and performance. Am J Public Health 2011; 101(10):1900-6. https://doi.org/10.2105/AJPH.2010.200915

[23] Maharani DA, Adiatman M, Rahardjo A, Burnside G, Pine C. An assessment of the impacts of child oral health in Indonesia and associations with self-esteem, school performance and perceived employability. BMC Oral Health 2017; 17(1):65. https://doi.org/10.1186/s12903-017-0358-5

[24] Maroneze MC, Ardenghi DM, Brondani M, Unfer B, Ardenghi TM. Dental treatment improves oral health-related quality of life of adolescents: a mixed methods approach. Int J Paed Dent 2019; 29(6):765-74. https://doi.org/10.1111/ipd.12548

[25] Busch V, Laninga-Wijnen L, Schrijvers AJP, De Leeuw JRJ. Associations of health behaviors, school performance and psychosocial problems in adolescents in The Netherlands. Health Promot Int 2015; 32(2):280-91. https://doi.org/10.1093/heapro/dav058 
[26] Reijntjes A, Stegge H, Terwogt MM, Kamphuis JH, Telch MJ. Children's coping with in vivo peer rejection: An experimental investigation. J Abnormal Child Psychol 2006; 34(6):873-85.

https://doi.org/10.1007/s10802-006-9061-8

[27] Almeida RF, Leal SC, Medonca JGA, Hilgert LA, Ribeiro APD. Oral health and school performance in a group of schoolchildren from the Federal District, Brazil. J Public Health Dent 2018; 78(4):306-12. https://doi.org/10.1111/jphd.12273

[28] Kaewkamnerdpong I, Krisdapong S. The associations of school oral health-related environments with oral health behaviours and dental caries in children. Caries Res 2018; 52(1-2):166-75. https://doi.org/10.1159/000485747

[29] Courtenay WH. Constructions of masculinity and their influence on men's well-being: a theory of gender and health. Soc Sci Med 2000; 50(10):1385-1401. https://doi.org/10.1016/s0277-9536(99)00390-1

[30] Galobardes B, Shaw M, Lawlor DA, Lynch JW, Smith GD. Indicators of socioeconomic position (part 2). J Epidemiol Community Health 2006; 60(2):95-101. https://doi.org/10.1136/jech.2004.028092

[31] Salama F, Alwohaibi A, Alabdullatif A, Alnasser A, Hafiz Z. Knowledge, behaviours and beliefs of parents regarding the oral health of their children. Eur J Paediatr Dent 2020; 21(2):103-9. https://doi.org/10.23804/ejpd.2020.2 1.02.03 